\title{
Museums and the Lightness of Life $^{1}$
}

GAYNOR KAVANAGH ${ }^{2}$

The concept of 'dream space', a term coined by Sheldon Annis in 1989, introduced the museums community to the idea that a significant element in experiencing museums is concerned with the unconscious mind. Whereas hitherto research has been directed at the cognitive and outwardly cultural, Annis's term 'dream space' has prompted examination of the affective and inwardly sentient (Kavanagh 2000). To understand more of the dream space, as a phenomenon of the way museums are envisaged and engaged with, is to ask questions about our subjective selves, individually and collectively, from psychological and other viewpoints. It follows that the concept of dream space begs questions about memory, emotional make-up, psychological states, life stage, life experience, cultural norms, ethnicity and gender. And it also raises questions about core beliefs and our relationship with what might be termed a spiritual dimension, however tenuous that might be for many. ${ }^{3}$

To understand something of the unconscious mind requires an ability to conceive of moving beyond or behind an objective reality where subjective and spontaneous responses or actions take place. In such places our minds work in very different ways, as they do when we are asleep or in meditation. To take the practice of meditation as an example, this is the gentle yet disciplined process of disengaging from the conscious mind. It involves reaching a state of altered consciousness where heightened alpha and theta brain wave activity is experienced. In deep meditation, there is a detachment, a loss of sense of self and the gain of a perceived spiritual reality. Writing about meditation, Sri
Swami Satchidananda (1978) said 'turning inside means turning the sense within; trying to hear something within, see something within, smell something within. All scents are within us. All beautiful music is within us. All art is within us. Why search, running after museums and gardens when every museum and garden is inside of us?'

What I take from all of this and from a now significant body of research on memory, identity and well-being, is that the museum in the mind is richer, lighter, darker and more powerful than anything that we can place in four walls, and that the museum as we know it is derived in part from our capacity to access our 
38 deeper selves - with all that means for remembering and forgetting, caring and discarding, making and ignoring meaning.

Understanding the cognitive and evident can only take us so far in understanding museums and our interactions with them. We need words to give meaning but, as lovers and enemies know, when we have meaning there comes a point when the words are thrown away; thoughts and actions will speak more eloquently than any semantic arrangement. In other words, cognition gives way to the eloquence of primal expression. The question therefore is - when museums end up with objects, i.e. non-verbal expressions, what is really taking place? Are they holding memories, or just a shade, a very thin shadow, of past meanings? Taking these shades, these very thin shadows, do we simply recast them into that which we wish to remember of ourselves today? Do we use them more to stabilise something not spoken about who we think we are, rather than reach out to those whose memories they are said to contain?

In thinking about this, and the significance and import of celebrating the British Museum's $250^{\text {th }}$ anniversary through an exhibition in 2003 - The Museum of the Mind; Art and Memory in World Cultures - I found myself forced back into some fundamental questions about the relationship between our lived lives and the material world we inhabit. Why do we cling to the object in the way we seem to do? Whether it is an aide memoir, keepsake, souvenir or memorial or mnemonic, we cling just the same. Why do we literally hold onto things? This raises hosts of questions not least about Western materialism and power, about personal articulation and cultural cosmology.

Czikszentmihalyi (1993) has argued that we have an addiction to objects that is best cured by learning to discipline consciousness. He says 'if one develops control over the processes of the mind, the need to keep thoughts and processes in shape by leaning on objects decreases.... A Brahmin can afford to live in an empty house, because he does not need objects to keep his mind on course'. The Brahmin living in a rich symbolic culture rather than one reliant on objectified consciousness explains this. But I am less convinced. Living in a rich symbolic culture did not prevent the Benedictine Order developing a fabulously wealthy, objectified consciousness, in spite of tremendous spiritual discipline. Maybe this is a different case, based as it is on Western rather than Eastern spiritual traditions and situated within profoundly different economic spheres. Nevertheless, the point is important: our relationship with the material worlds we build for ourselves is grounded in our sense of selves, built from an inner core.

In thinking about this, I am lead back to some of the language I have already been using and this is the language of tactility. Why do we hold on to things? Why do memories cling? In this paper, I would like to address the notion of tactility, our sense of touch and physical connection with the material world.

A scene from the film Star Trek: First Contact (1996) encapsulates something of this. The Captain and the android Data, along with the crew of Star Ship Enterprise, have been forced back in time to the moment when warp power is at the point of invention. The two characters find themselves face to face with the Phoenix, the prototype warp ship. In the future and in their own time, this is held in the Smithsonian, revered and celebrated. In this scene, it stands in a shed ready for its test run. The Captain, in awe, speaks of his long held but thwarted desire to touch it. He remembers his former-self visiting the Smithsonian and the 
role of the museum in preventing that touch. Now able to touch, he places his hand on the body of the engine and falls quiet. Data does the same and unable to get more than a reading on its titanium levels is totally confused by the Captain's state of unspoken reverie and the obvious effects of the touch, now permitted. The scene is interrupted and brought to a conclusion by another character Deanna Troy, who apologies for interrupting the 'touch-fest' between the three of them (thereby acknowledging the object as the third and equal party in this) and hurries them on. That such a scene should be incorporated into mainstream media is testimony to a common understanding about iconic objects, their place in museums, the prohibitions museums place on the visitor, and the thwarted need to touch things that have meaning.

Within museum debate, there is acknowledgement of the basic and direct contradictions embedded in the imperative to safeguard and protect special objects whilst at the same time enabling meaningful access. The former Director of Glasgow museums, Julian Spalding referred to there being essentially two groups of curators: the carers and the sharers, by definition at odds with one another. Arguably the great curators are those sufficiently inspired to find ways of both caring for and sharing collections. Instinctively, many museum professionals know how the experience of touching objects in collections can be a special experience. In a televised interview, Neil McGregor, Director of the British Museum, shortly after his appointment and in the midst of talking about the importance of the BM's collections, described a handling session held in one of the galleries. At this point his eyes lit up as he talked animatedly about the experience of actually being able to hold things.
So how can we begin to understand the power of touch? Indeed what is touch and what does it mean to us? This has to begin with thoughts about our skin - our largest organ.

Many years ago there was a comedy song about skin, a childrens' favourite sung by Bernard Breslow, one of the lines of which was about how we need skin to keep our insides in. The place of the skin as the edge of containment is captured in Erica Jong's poem from 1981 'At the Edge of the Body' and the lines

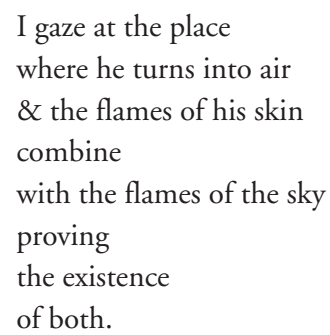

Our skin holds us together and gives us away. It defines where we end and our world begins. It is the transmitter for a huge repertoire of feelings and sensations. We can go pale with fear and flush with embarrassment. We touch tenderly with love or roughly with anger. We use it to feel certain of the existence of others and to let others know of our certainty of their presence. Through our skin comes all we understand of warm and chill; pain and pressure; the textures of scrape, abrasion, kiss and hug; the senses of tickle, lick and stroke; the knowledge of perforation and indentation; of silk sheets and iron railings, of a calloused hand, a clenched fist, unspoken gestures of solidarity, friendship, unconditional love. It is the medium through which we receive the most fundamental information, whilst at the same time being the medium through which we indicate our most essential emotional conditions.

Because we experience life so much through 
40 touch, inevitably our memories are not just visual, olfactory and echoic, they are tactile too and equally informing. If I ask you to conjure in your minds now the differences of sensation between slipping into the sea on the most fabulously beautiful summer's day, pulling a much loved book from a shelf, and thrusting a spade or trowel into the earth, I suspect such images would be real and accessible in your minds. But if I ask you to contemplate kissing the spiny back of a hedgehog, licking a piece of sandpaper, or sitting in a cow pat, you would need no experience of these things to have some reaction. You could imagine it well enough, using as points of reference not only your knowledge of hedgehogs, sandpaper and cowpats, but also some of your better experiences of kissing, licking and sitting.

Sensory experience is essential to the laying down and retrieval of memories. The detail and scope of that which we remember, and the cues that prompt recall, are determined in good part by what is known as encodement specificity. Memories are about a whole range of things, layered and overlapped. Not just the episode, but the feelings and senses that went with it. Not just the bike ride, but the smell of summer meadows, the sounds of dogs barking and tyres on tarmac, the feelings of falling and the scrape on the knee, the tumble into the nettles, the thud of the bike's handlebars landing on the ground next to your ear. Any one of the sensory cues could bring the episode back. To use the jargon, what is experienced here is crossmodel.

Diane Ackerman (1990) argues that touch is not only basic to our species - it is key to it. In foetuses, touch is the first sense to develop. Newborns not yet orientated to the world, instinctively begin with touching, clutching, reaching out. Children, who grow without the regular assurance of affection through touch, tend to be more aggressive and less adaptable to productive relationships. In adulthood, to live without receiving genuine regard through touch can be seriously debilitating and depressive.

In essence, touch assures us that we are not isolated. It corroborates the difference between ourselves and others. It verifies the reality of our worlds, of our relationships and our first hand experiences. It gives us the unquestionable evidence of our living a life. Through touch we know when something is hot/cold, hard/ soft, living/dead, serrated/polished, sharp/dull, caring/hostile, kind/ unkind, benign/malignant, threatening/supportive. Simply put, we know our worlds because we can touch them and they touch us. It is authentication, transference and confirmation. Indeed the relationship of touch to our ability to understand and negotiate something of life is expressed in the very language that we use. For example the verb 'conceive' is from the Latin 'concipere' - meaning to take and hold, hence 'to conceive' means to become pregnant, to beget. This can of course be figurative as in - to form in the mind or to formulate an idea. Other examples would be the verbs to grasp, apprehend, brood, and ruminate.

Museum practice has become increasingly informed by research into the different ways in which meaning is made through objects and collections. This has resulted in a greater preparedness to engage directly with people's experiences, rather than assuming that the museum simply provides for them. It is beginning to bring about in some areas of museum work a new kind of emotional literacy, arguably long absent.

This preparedness to connect more fully with the potential of museums has stemmed from a gradual transition in museum thinking and 
practice. There is now arguably a greater recognition of the need to listen to what people are saying, whether this is of themselves today, or in oral history or in carefully planned therapeutic reminiscence and outreach. There is also a braver and more honest recognition that culture is not just beautiful and complex, but is also downright ruthless and heartbreaking. Moreover there is the acceptance that collections are not neutral, that they have been crafted and then re-crafted in there own cultural and political likeness. They carry as much of our stories of now, as they do of evidence of their origins and passage through time.

Museum thinking has also become to grasp that visitors are subversive readers of the exhibition's message - we as visitors make our own meanings of what we see and experience, forever disrupting, ignoring or challenging the cognitive agenda of the museum. Our own stories are brought to the experience of museums and their collections and act as the mediation or filters for all that we choose to take away from the experience. Shaped by our time and place, we as visitors employ the museum experience within our life patterns and not the other way round. Museums arguably have an enabling role in relation to the visitor, but the visitor has the last word in what if anything they want to do with this.

The constructivist view of literature heralded the debate about the death of the author. So too (but to a far limited extent) the constructivist view of museum learning has heralded debate about not quite the death of the curator, but certainly the limitations of their intended communication through exhibitions. One aspect of this has been a more ready grasp of the concept of objects being poly-semantic, i.e. that objects have a whole host of meanings and associations. The single-naming procedu- re central to all museum collections and their catalogues is utterly confounded when questions about poly-semantic meanings are brought to bear. Perhaps it is because they are poly-semantic and that we know that there is bound to be a shifting meaning to each (not less than a shifting pattern of meaning within our lives), that we seek verification and confirmation of the meanings we ascribe - and we do this by reaching out to touch.

With this in mind, we can hardly fail to notice the extent to which all our lives witness or directly engage with rituals of touch as a means of relating. In this there is an odd balance of relationships: one of the animate to the inanimate. For whatever reason and in whatever situation, touch is a primal human act. The purposes and agenda lay with us, not the object. The object by definition is inanimate and cannot respond in kind. The projections can only be entirely human. The conclusions drawn from such experiences are our own. Whereas generations of museum curators may have asserted the mantra that 'objects speak for themselves', this is a difficult notion to sustain with any rigour or indeed an entirely straight face.

Admittedly, there are people who will profoundly disagree with this. There is a strongly held belief that objects literally carry the resonances, the energies or auras of their histories, and that it is these with which we commune on a highly-tuned psychic level. By touching objects and by allowing a suspension of objectivity, we reach meanings that only such communion can achieve. This may go to an extreme. Lyall Watson in The Nature of Things recounts 'every time Ian Moncrieffe in Bristol boils his electric kettle, he receives mystic messages. In Norfolk, Janet Barker's new cooker talks to her in Dutch. Office-cleaner Madge Gunn in London gets silly orders from her va- 
42 cuum cleaner.... Doris Gibbons' electric meter is more polite' (Watson 1990).

To pursue arguments that objects carry past energies or present auras is to move the discussion into the realms of faith and observance, to the subjective engagement with ritual or belief. Here the touching of objects is much more than verification or orientation, a means of getting bearings on who and when we are. It is an act concerned with intercession, a means of reaching something beyond. Here the object is used as a means of 'transmission' or mediation between the person and their belief, their God. This has lain at the heart of the material development of faith, in the setting of space and objects as a means of reaching something of the divine.

In theological terms, there is much academic debate regarding whether objects can be intrinsically sacred or whether human beings sacrilise them. Christianity, but especially Protestantism, has taken a rather equivocal view of the sacrilisation of objects, because of the desire to distance itself from magic. The historian Keith Thomas' major study Religion and the Decline of Magic (1974) disclosed how a dominating structured religion marginalises, even eliminates, inconsistent practices and beliefs as magic. By the same token, when organised religion fails, organic and 'magic' beliefs emerge. Contemporary New Age beliefs put much stress on intrinsic energies within objects, people and places. We now live in an age where belief in the spirit-power of objects is confidently discussed.

Objects as vehicles for intercession are not just evident in formal religious observances. They are evident in the personal and spontaneous, where arguably the touch becomes a central part in individual and personal acts of intercession. In more recent years in the UK, a response to the loss of a loved one in a road crash has been to place flowers at the spot where the crash occurred. Families renew these votive offerings, a way of maintaining a communion with their loved one at the specific spot where their lives were ended. The flowers are a symbolic form of their intercession at a place that for them holds huge power through its significance in tragedy. The act of their placement and their touch with it are a continuing matter of faith.

Touch in this regard can be concerned with shifting cultural patterns and new beliefs, even magic and the decline in religion, to reverse Thomas's title. In the 1970s the megaliths, quoits and stone circles to be found in the West of Cornwall were referred to as 'antiquities', visited by a relative few in search of something of the county's archaeology. Three decades later, they are now being referred to as 'sacred sites' and are visited much more frequently. Many who visit now perform their own rituals of touch, leaving behind flowers, shells and fragments of cloth in solemn acts of reverence. At a time where more varied and individually directed forms of faith practice is common, new purpose is being ascribed to the stones and new meaning being derived from touching them.

In the light of all of this, how might the need to touch be understood? Perhaps the central point is that to touch something is in essence to aid an inner dialogue. The more significant the object is to a person, the more profound or important the inner dialogue facilitated by the touch. Thus family photographs albums and memorabilia, the souvenirs of life sifted and stored away, are effective prompts. It is not simply seeing them, it is the holding of them, that precipitates recall, reflection and sometimes not a little feeling.

Perception of significance changes over time, 


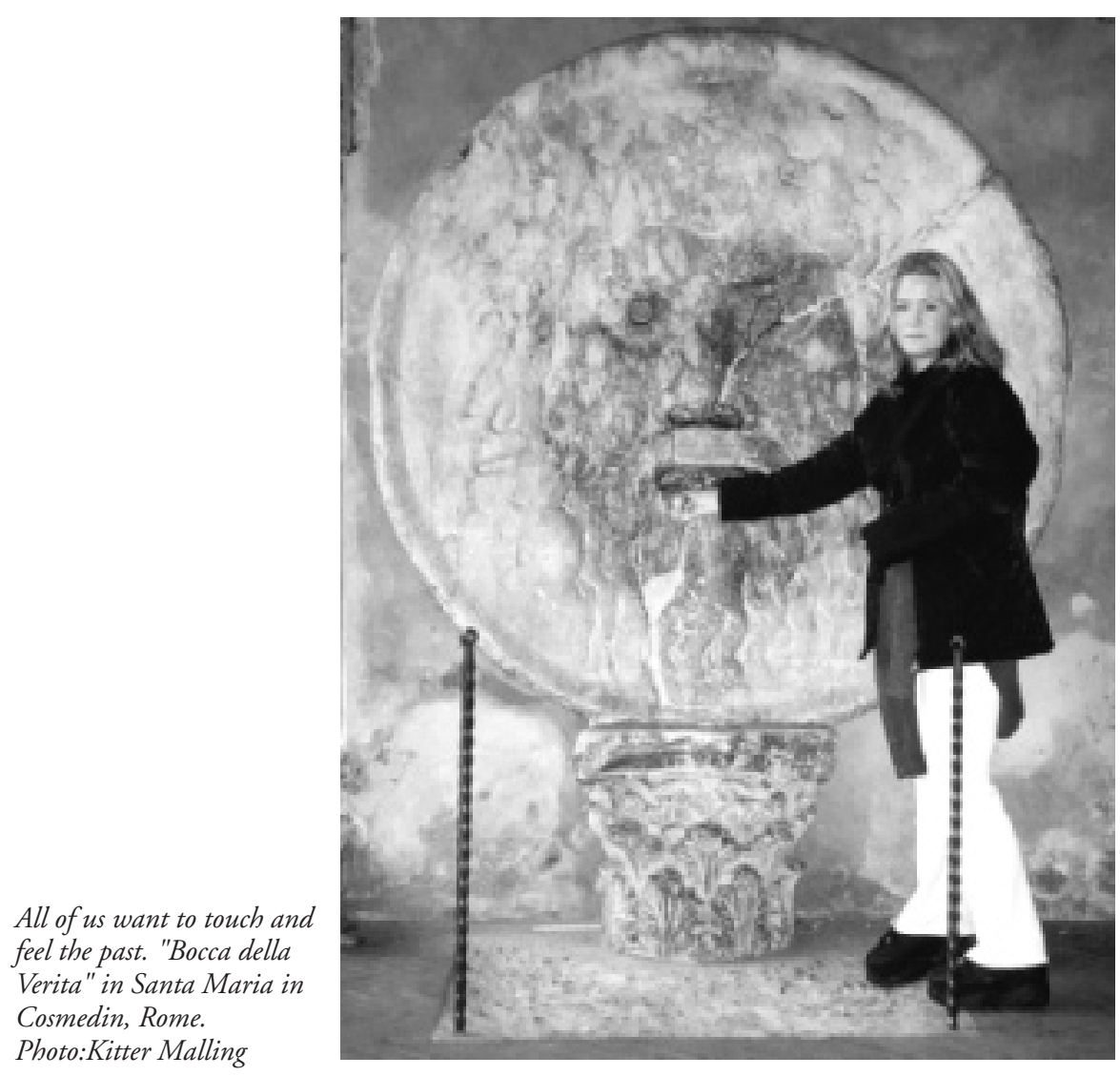

and with this the imperatives and purposes of touch. The memorabilia of a wedding changes substantially in significance when the marriage fails. Feelings towards school records of indifferent achievement change in the face of high accomplishment in later life. The material that evidences associations with fashions of thinking, clothing and people may become the subject of embarrassment and disassociation or considerable pride. Not all the personal things we touch, we touch with fondness. Other issues play - such as bitterness, regret, loss, indifference.
Arguably, this experience of connection and disconnection through touch, although most vivid in a more personal context, operates in the outer world with equal effect. Not only does significance change over time, it can of course be learnt. Museum education officers work to introduce new and important ideas to people through objects in ways that enable those ideas to be developed and further explored. Thus the handling sessions at the British Museum, the source of the Director's delight in the documentary mentioned above, are a means of enabling learnt significance to be achieved th- 
44 rough touch and beyond this a connection to new or enhanced fields of knowledge.

Whether the notion of significance can be situated in the personal or public moment, if we take the view that nurture is as important as nature, it must draw on much beyond an individual's inner territories and resources. We all live in defined cultural moments and exist within political circumstances that continuously confine, shape and dictate who and what we are. The relationship of the personal to the public, the small scale and intimate to the major and communal, is a component of how we approach the museum as one of many types of socially significant places. This dynamic between the personal and the public is evident particularly where something of the extremes of life are encapsulated, such as sites of commemoration.

The Vietnam War Memorial in Washington, designed by Maya Lin, is much visited. For many there is a considerable personal significance, for others it is a stop on the tourist routes around Washington. Designed to be intimate and on a human scale, the monument carries the names of those Americans killed in Vietnam, in the chronological order of their deaths. Its highly reflective surface ensures that visitors have to see themselves when they look at it. For those who find names of family, friends or comrades there, the need to touch is irresistible. Touching the Wall is a central part of the visit. People 'take away' the touch, by tracing the names on its surface. Artists have expressed this touch with images of greying men in city suits with bowed heads touching the names of comrades killed whilst at the same moment their comrade's ghostly image, caught in time young and in the company of others, reaches out to return the touch through the Wall. Intercession through touch, is augmen- ted by the leaving of things (regularly gathered and deposited in the Smithsonian)- flowers, messages, photographs, even a Harley Davison bike. The Wall confirms the reality of death and loss, trauma and the passage of time. It can be a conduit for grief and hence is used therapeutically in the care and support of Vietnam Veterans. It can also be seen as a way of not touching another aspect of the War and that is the shattered lives of the men who returned and their continued struggle with the infinite trauma of it all (Tritle 2000).

In the mid-1990s, there was a proposal on the island of Guernsey to have a plaque commemorating those who had died there in forced labour during the Second World War. Inevitably, the names would include those of Germans who were forced into labour there. The names of German dead were not welcomed, by some - even though these were forced labour, with all that that meant, and not combatants. The bitterness felt was still very deep. A campaign ensued, led by Mr William Underwood, to have the names removed - to expunge the record, to cover it up, to mask, to obliterate. The press coverage carried an image of $\mathrm{Mr}$ Underwood covering the names on the plaque with his hands, signally the denial of touch.

To touch implies possession. To be able to touch something is to operate within a set of permissive circumstances, defined by ownership. Thus, for example, a museum decides which if any object can be touched, or a heritage site determines how it is to be accessed. The exclusion of people from the immediate vicinity of Stonehenge is a case in point (Bender 1998).

By extension, obliteration is the ultimate denial of touch and therefore possession. Wilful obliteration aims to terminate self-referen- 
ce and discovery, for making new forms of meaning, for drawing new knowledge, from stressing the forming processes of continuity and discontinuity, for exposing hypocrisy and recovering the voices of the unheard. It aims to reorder the past, by eliminating that which exists as token of it, and by so doing destabilise the very sense of self-definition, of connection, of touching all that there is.

This happens with vicious intent in wartime. The fundamental brutality of every war is such that, by definition, it involves the destruction of those places and things that have deep meaning for the opposing protagonists. The bombing of Dresden and Coventry and the destruction or spoliation of libraries and art collections held by European Jewry in the second World War, to the destruction of the two Bamiyan Buddhas in Afghanistan in February 2001 and the loss of archaeological and manuscript collections in Iraq in April 2003, are just a small part of a heartbreaking catalogue of obliteration as a tool of war.

Sadly, obliteration can take a number of other forms and is not confined to the deliberate and hate-filled. Sheer negligence is another route to obliteration; the inevitable outcome where objects are held in environmental conditions that can do no other than promote rapid deterioration. In such circumstances, the material held is deemed insufficiently important to warrant the investment needed for survival. Through the ignorance or simply poor judgment that underpin negligence, countries have lost buildings, structures, records and objects that are now recognised to have been of tremendous significance.

There is also obliteration through deliberate choice, where evidence of the marginalised, disposed and disallowed falls beyond record, beyond retention. Society's 'untouchables' have been repeatedly excluded from the record, from having things of theirs kept for us to touch. Thus, as a result, museum collections are made up of the socially significant, the perceived higher forms, the voices of the powerful, the work of the best makers, the most beautiful, the least mundane, the less troublesome. We can't know them, because we can't touch them. In tandem with this is the way that museums have placed beyond touch and more importantly beyond appropriate observances the special objects, even the very bones, of marginalised peoples.

So near the conclusion, important questions remain: why do we cling to solidity? Is it all about our materialist western ways, the absence of spiritual certainty, or something else, perhaps something quite profound, even awful? This is not an easy question to answer, but maybe something of what this is about lies in T.S. Eliot's poem A Song For Simeon, from which I take these lines

My life is light, waiting for the death wind,

Like a feather on the back of my hand.

Dust in sunlight and memory in corners

Wait for the wind that chills towards the dead land.

If we take this poetic image and imagine our outstretched hand with a feather gently balanced on its back, we might feel its tickle, see the light shining through it, and be aware of its gentle contact on the skin. From here it is possible to consider how easy, how inevitable it is for that feather to be lifted by even the gentlest of breezes, let alone the cold ferocity of the death wind.

From this, it seems to me that touch is our guarantee of connectedness to life itself. Because we know our lives are vulnerable and must eventually like the feather be lifted from us, we seek to weight them down, anchor them with things, things we check and double-check 
by touching, holding and guarding. Their weight is a guarantee of our longevity.

But deep down we know this can only work for a while, our lives are as light as that feather. What we leave behind are the ballasted things we once thought of as us. Through these things we leave behind traces of the best and the worst of us, both the mundane and the exceptional. They are the evidence of us, in whatever form they take - manuscripts, images, objects, spaces and places. Those who come after us will arrange and re-arrange them, question, compare and analyse them, not only in memory of us and what we represent to them, but also within the idea of themselves and what they seek to find in their lives, whether this be in the next decade, century or millennium. Because these are the things we touched, they will touch them too. They will find a reality in that touch and from it, for good or ill, construct a world of meaning about who we were then and - more important - who they are now.

\section{Notes}

1. I am very pleased to contribute a paper to this special volume of Nordisk Museologi, dedicated to Per-Uno Agren. He is a friend and inspiration to many people in the museums world, not least to me. His commitment to making museums better and more interesting places has encourages all of us to think more clearly and more imaginatively. It's a wonderful legacy. Thank you Per-Uno.

2. This paper is based on a lecture given at the British Museum in May 2003 as part of the celebrations of the BM's 250 anniversary.

3. I am grateful to Kay Millard for our conversations on intercession and for her thoughts on this paper in draft form.

\section{REFERENCES}

Ackerman, D. (1990) A Natural History of the Senses, Phoenix, London

Annis, S. (1987) 'The museum as a staging ground for symbolic action' Museum, 151, 168-71

Bender, B. (1998) Stonehenge: Making Space, Berg Publishers, London

Csikszentmihalyi, M.(1993) 'Why we need things' in Lubar, S. and Kingery, W.D. (eds) History from Things: Essays on Material Culture, 20-29, Smithsonian Institution Press, Washington

Eliot, T.S. (1954) Selected Poems, Faber and Faber, London

Jong, E. (1981) At the Edge of the Body, Granada, London

Kavanagh, G. (2000) Dream Spaces: Memory and the Museum Leicester University Press, Leicester

Mack, J. (2003) The Museum of the Mind: Art and Memory in World Cultures, British Museum Press, London

Satchidananda, Sri Swami (1978) The Yoga Sutras of Patanjali, Integral Yoga Publications, Buckingham, Virginia

Thomas, K. (1971) Religion and the Decline of Magic, Penguin, London

Tritle, L. (2000) From Melos to My Lai, Routledge, London

Watson, L. (1990) The Nature of Things, Hodder and Stoughton, London

Dr Gaynor Kavanagh lectures in museum studies at the University of Southampton. She is the author of Dream Spaces: Memory and the Museum (LUP 2000), Museums and the First World War (LUP 1994), and History Curatorship (LUP 1990).

E-mail address: gaynor.kavanagh@btinternet.com 